\title{
The Combination of Phyllanthus niruri, Euphorbia hirta, and Loranthus sp. as a Source of Antioxidant Agents
}

\author{
Elizabeth Betty Elok Kristiani, Sri Kasmiyati*
}

\author{
Faculty of Biology, Universitas Kristen Satya Wacana, Indonesia \\ *Corresponding Author: kas@uksw.edu
}

Submitted: 2021-06-15. Revised: 2021-07-28. Accepted: 2021-08-16

\begin{abstract}
Meniran (Phyllanthus niruri), patikan kebo (Euphorbia hirta), and benalu (Loranthus sp.) have often been used by people as medicinal plants. This research aimed to measure the levels of flavonoids, phenolics, and ascorbic acid compounds, as well as the Free Radical Scavenging (FRS) activity of ethyl acetate extract from the mixture of $P$. niruri, E. hirta, and Loranthus sp. The FRS activity was measured with the 2,2-diphenyl-1-picrylhydrazyl (DPPH) method. The level of compounds was measured by using the spectrophotometry method with specific reagents. The result of the FRS activity in ethyl acetate extract from the mixture of $P$. niruri, E. hirta, and Loranthus sp. varied depending on its dose. The measure of FRS in the P. niruri: E. hirta: Loranthus sp 0:0:1 (K-OOL) composition showed a strong result with a value of $\mathrm{IC}_{50} 97.2 \pm 2.1 \mathrm{ppm}$, while in the 0:0.5:0.5 (K-OEL) composition it was moderate with a value of $\mathrm{IC}_{50} 147.6 \pm 6.5 \mathrm{ppm}$. The other compositions showed weak and inactive results. The K-OOL composition had the highest flavonoid and phenolic content that were $298.8 \pm 0.00 \mathrm{mg} \mathrm{QE} / \mathrm{g}$ extract and $141.5 \pm 2.85 \mathrm{mg}$ GAE/g extract respectively. The composition with the highest ascorbic acid content $(298.8 \pm 0.00 \mathrm{mg} / \mathrm{g}$ extract) was K-OEO composition. So far, research on medicinal plants is still limited to one type of plant. The combination of several types of plants in several formulations allows obtaining a composition that can produce maximum antioxidant capacity. Therefore, this research is expected to produce a combination formulation of various types of medicinal plants that have the K-OOL composition very strong antioxidant activity and can be used as herbal medicines.
\end{abstract}

Key words: antioxidant; secondary metabolites; Phyllanthus niruri; Euphorbia hirta; Loranthus sp.

How to Cite: Kristiani, E. B. E., \& Kasmiyati, S. (2021). The Combination of Phyllanthus niruri, Euphorbia hirta, and Loranthus sp. as a Source of Antioxidant Agents. Biosaintifika: Journal of Biology \& Biology Education, 13(2), 201-211.

DOI: http://dx.doi.org/10.15294/biosaintifika.v13i2.30718

\section{INTRODUCTION}

Medicinal plants play an important role in treating human's health disorders (Sofowora et al., 2013). The history has shown that ever since the ancient times, humans have been utilizing natural ingredients to cure diseases and preserve health. Commonly, they turn various types of herbal plants into medicinal potions to use whether as a treatment or prevention. In Indonesia, medicinal potions are known as Jamu. The traditional use of herbal medicine is rooted in the cultural practices and customs that was passed from generation to generation (Mahmood et al., 2011). At present days, the role of medicinal plants is rising because of their ability to cure various diseases. These abilities are related to the presence of secondary metabolites in plants (Petrovska, 2012). Plants are excellent sources of secondary metabolites such as phenolics, flavonoids, alkaloids, lignans, and terpenoids (Karakaya et al., 2019). The various capabilities of secondary metabolites in plants including as sedative (Bahmani et al., 2019), antibacterial (Ibrahim et al., 2013; Kasmiyati et al., 2021) antispasmodic (Martinez-Perez et al., 2018), antidepressant (Eloziia et al., 2017; Rahman et al., 2017), anticancer (Kristiani et al., 2016; Middleton et al., 2000; Kristiani et al., 2021), anti-inflammatory, analgesic, antipyretic, hepatoprotective, and nephritic (Yusufoglu, 2014; Haidara et al., 2020), analgesic, immunomodulatory, and/or antioxidant properties (Majid et al., 2015; Safriani et al, 2021). Currently, many studies have been carried out to scientifically prove the efficacy of medicinal plants for health.

Antioxidants are compounds that slow down or prevent oxidation so as to prolong the life of oxidizable materials. The majority of human's diseases or health disorders are mainly related to oxidation, specifically due to a free radical activity (Kumar \& Pandey, 2015). Exogenous intake of antioxidant sources can help repair the damage caused by oxidative stress by slowing down the initiation or propagation of oxidative chain reactions, free radical of scavenging, an absorber singlet oxygen or other the agents of reduction (Baiano \& Nobile, 2015). Exogenous antioxidants can derive from food such as fruits, flowers, vegetables, and cereals, or from traditional herbs which are generally a mixture of spices (Deng et al., 2012).

There are various scientific studies of the antioxidant activity of some plants that have been used by people for their health benefits. Meniran (Phyllanthus niruri), patikan kebo (Euphorbia hirta), and benalu (Loranthus sp.) have been widely used by 
people as medicinal plants. Based on the the results of those studies by several researchers, the differences of solvent affect the phytopharmaceutical ability of plant extracts because of the different bioactive compounds extracted. Ethyl acetate extracts, either direct or by fractionation, were reported to show strong antioxidant activity, such as on the roots of Phyllanthus amarus (Maity et al., 2013), Euphorbia dracunculoides (Majid et al., 2015), as well as on the bark, leaves, and seeds of Loranthus pulverulentus (Raza et al., 2013).

Several secondary metabolites have been found to exhibit free radical scavenging activity, such as polyphenols (phenolic acids, flavonoids, anthocyanins, lignins, and stibenes), carotenoids (xanthophylls and carotenes), and vitamins (vitamins $\mathrm{C}$ and E) (Xu et al., 2017). Wafaa et al. (2016) also reported an antioxidant activity from flavonoid and tannin compounds. Meanwhile, phenolic compounds from the methanol extract of the leafy twigs of Loranthus micranthus showed the most potent free radical scavenging ability among other compounds (Zainol et al., 2003).

In daily practice, the herbal preparation of medicine was consisting of more than one type of material. Each material will have different phytopharmaceutical active ingredients so that enables interactions in their activities. So far, the study of medicinal plants has been limited to a single plant species. The combination of several types of plants in several formulations allows the acquirement of a composition that can produce maximum antioxidant capacity. Therefore, this research is expected to produce a combination formulation of various types of medicinal plants that have very strong antioxidant activity and can be used as herbal medicines. This study aimed to measure the levels of flavonoid, phenolic, and ascorbic acid compounds, as well as the antioxidant activity of the combination of ethyl acetate extract of Phyllanthus niruri, Euphorbia hirta, and Loranthus sp.

\section{METHODS}

This research was carried out in October to December 2020, at the Laboratory of Biochemistry and Molecular Biology, Faculty of Biology, Satya Wacana Christian University, Salatiga. The main materials of $P$. niruri, E. hirta, and Loranthus sp. weeds (Figure 1) were taken at the Satya Wacana Christian University campus in Salatiga. Each sample composition was extracted by maceration using ethyl acetate as solvent. Parameters measured including the total bioactive compounds content that were flavonoid, phenolics, and ascorbic acid, as well as Free Radical Scavenging (FRS) activity. Before the mixing was conducted, each plant was dried first (Figure 1) and then made into dry simplicia powder. The mixing of materials is presented in Table 1.



Figure 1. Plants used in the study. (A-C) Fresh plants were taken from the sampling location; (D-F) Plant dry simplicia; (A and D) Meniran (Phyllanthus niruri); (B and E) Patikan kebo (Euphorbia hirta); and (C and F) Benalu (Loranthus sp).

Table 1. The combinations of Phyllanthus niruri, Euphorbia hirta, and Loranthus sp. used as research samples.

\begin{tabular}{lccc}
\hline & \multicolumn{3}{c}{ Ratio of combination } \\
\cline { 2 - 4 } Combination & $\begin{array}{c}\text { Phyllanthus } \\
\text { niruri }\end{array}$ & $\begin{array}{c}\text { Euphorbia } \\
\text { hirta }\end{array}$ & $\begin{array}{c}\text { Loranthus } \\
\text { sp. }\end{array}$ \\
\hline K-POO & 1 & 0 & 0 \\
K-OEO & 0 & 1 & 0 \\
K-OOL & 0 & 0 & 1 \\
K-PEO & 0.5 & 0.5 & 0 \\
K-POL & 0.5 & 0 & 0.5 \\
K-OEL & 0 & 0.5 & 0.5 \\
K-PEL & 0.33 & 0.33 & 0.33 \\
\hline
\end{tabular}

\section{Preparation of extracts}

Ethyl acetate was added to the dry powder of each combination until it completely submerged. The mixture was macerated for three hours while being shaken using a magnetic stirrer. The maceration result was filtered using a filter paper and the filtrate was set aside. The maceration process was repeated until the immersion filtrate appeared clear. All filtrate was combined and then concentrated using a rotary evaporator (Rotavapor R-114 Buchi) with the help of a vacuum pump (Eyela A-1000S). The concentrated extract was ready for further analysis.

\section{Total flavonoid content assay}

The total flavonoid content was measured by the $\mathrm{AlCl} 3$ method (John et al., 2014). Quercetin was used as a standard for flavonoid compounds in the concentration range of $0-100 \mathrm{ppm}$. A total of $1.0 \mathrm{ml}$ of sample was added with $0.3 \mathrm{ml}$ of $10 \% \mathrm{AlCl} 3$ and was incubated for 5 minutes. After that, $0.3 \mathrm{ml}$ of $5 \%$ 
$\mathrm{NaNO} 2$ was added and was incubated for another 5 minutes. In the final step, $2.0 \mathrm{ml}$ of $1 \mathrm{M} \mathrm{NaOH}$ was added. The absorption of the mixture was measured using an ultraviolet-visible spectrophotometer (Shimadzu Mini 1240 UV spectrophotometer) at a wavelength of $510 \mathrm{~nm}$. The measurement results of the absorption of the quercetin solution were represented in a linear regression equation. The flavonoid level in the sample was determined based on the quercetin standard curve equation.

\section{Total phenolic content assay}

The total phenol content was determined using the Folin Ciocalteau method (Almey et al., 2010) with gallic acid as the standard for the phenolic compounds. A total of $1.0 \mathrm{ml}$ of sample was added with $1.0 \mathrm{ml}$ of Folin Calteau reagent and incubated for 5 minutes. After that, $10 \mathrm{ml}$ of $7 \% \mathrm{Na} 2 \mathrm{CO} 3$ was added next and incubated for 90 minutes. The absorption of the mixture was measured using an ultraviolet-visible spectrophotometer (Shimadzu Mini 1240 UV spectrophotometer) at a wavelength of 550 $\mathrm{nm}$. The measurement results of the absorption of the gallic acid solution were represented in a linear regression equation. The total of the flavonoid was calculated based on the standard curve equation of gallic acid.

\section{Ascorbic acid content assay}

The ascorbic acid content testing was based on the research done by Balogh and Szarka (2016). The ascorbic acid level was measured with the sulfosalicylic acid method. An amount of $1.0 \mathrm{ml}$ sample was added with $3.0 \mathrm{ml}$ of sulfosalicylic acid, $2 \mathrm{ml}$ of Na-molybdate, $2 \mathrm{ml}$ of $0.15 \mathrm{~N} \mathrm{H} 2 \mathrm{SO} 4$, and 1 $\mathrm{ml}$ of $1.5 \mathrm{mM}$ Na2HPO4. The absorption of the mixture was measured using an ultraviolet-visible spectrophotometer (Shimadzu Mini 1240 UV spectrophotometer) at a wavelength of $550 \mathrm{~nm}$. The measurement results of the absorption of the ascorbic acid standard solution were represented in a linear regression equation. The total level of the ascorbic acid was calculated based on the standard curve equation of ascorbic acid.

\section{Free Radical Scavenging (FRS) activity assay}

The FRS activity was measured by using the DPPH method (Chan et al., 2007). Ascorbic acid was used as a standard free radical scavenging agent. The series of sample concentrations were in the range of $0.001-0.1 \mathrm{~g} / \mathrm{ml}$. A total of $1 \mathrm{ml}$ of the sample was added with $2 \mathrm{ml}$ of DPPH (1.1-diphenyl-2picrylhydrazyl) $50 \mathrm{ppm}$ in methanol. The mixture was incubated in the dark for 30 minutes and its absorbance was measured using an ultraviolet-visible spectrophotometer (Shimadzu Mini 1240 UV spectrophotometer) at a wavelength of $517 \mathrm{~nm}$. The value of the FRS activity was calculated using the equation $=1$ - (sample absorption / standard uptake) $\mathrm{x}$ $100 \%$. The absorption data for each test concentration was represented in a linear regression equation, and the $\mathrm{IC}_{50}$ value was then determined.

\section{Data analysis}

The differences in $\mathrm{IC}_{50}$ values and test compound content between extracts were analyzed statistically through analysis of variance (ANOVA) using SAS ver. 9.1.3. If there was a significant effect between the treatment and the control, the test was then continued with the Tukey's test at the 5\% test level. All experiments were carried out in five replicates.

\section{RESULTS AND DISCUSSION}

\section{Free Radical Scavenging (FRS) activity}

Antioxidants are molecules that are able to inhibit the oxidation of other molecules by donating its electrons so as to break the chain of free radical reactions (Dontha, 2016). In general, in vitro antioxidant tests using free radical traps are relatively easy to do. In this study, the antioxidant ability of the extract was tested in vitro using 2,2-Diphenyl-1picrylhydrazyl (DPPH), a stable free radical. The DPPH method is one of the most widely used free radical scavenging method because the steps are simple, fast by using an ultraviolet-visible spectrophotometer, and low in cost (Dontha, 2016; Burda \& Oleszek, 2001). In this test, DPPH as a stable radical (purple color) will be reduced by the presence of an antioxidant compound into a radical form of DPPH-H which gives a yellow color. The more color removal there is, the greater the ability to reduce free radical scavenging of antioxidant compounds (Bandoniene \& Murkovic, 2002). The antioxidant ability test using the DPPH method is expressed through the ability to inhibit free radicals (PRB). Ascorbic acid or commonly known as vitamin $\mathrm{C}$ is used as a standard antioxidant compound. Vitamin $\mathrm{C}$ is a non-enzymatic antioxidant group which the mechanism interferes the free radical chain reactions (Dontha, 2016).

The results have shown that the FRS activity of the mixed extract of the three weeds was dose dependent, in which the higher the concentration of the extract was, the greater the FRS activity (Figure 2 ). Figure 2 shows that a single extract composition of Loranthus sp. or the composition of P. niruri: $E$. hirta: Loranthus sp. 0:0:1 (K-OOL) and the composition of $P$. niruri: E. hirta: Loranthus $\mathrm{sp}$ 0:0.5:0.5 (K-OEL) have a greater antioxidant activity than other compositions. 




Figure 2. Graph of the dose-dependent relationship between extract concentration and FRS activity of the mixed extract of Phyllanthus niruri, Euphorbia hirta, and Loranthus sp. combination. The ratio of $P$. niruri: E. hirta: Loranthus sp. in K-POO = 1:0:0, K-OEO = $0: 1: 0, \mathrm{~K}-\mathrm{OOL}=0: 0: 1, \mathrm{~K}-\mathrm{PEO}=0.5: 0.5: 0, \mathrm{~K}-\mathrm{POL}=$ $0.5: 0: 0.5, \quad \mathrm{~K}-\mathrm{OEL}=0: 0.5: 0.5$, and $\mathrm{K}-\mathrm{PEL}=$ $0.33: 0.33: 0.33$.

The antioxidant activity of a material is expressed through how much the value of antioxidant concentration required to inhibit $50 \%$ of free radical compounds, or commonly referred to as the $\mathrm{IC}_{50}$ value. The category of the antioxidant strength of a material can be determined based on the $\mathrm{IC}_{50}$ value (Jun et al., 2003). The $\mathrm{IC}_{50}$ value and antioxidant strength of each mixture of $P$. niruri, E. hirta, and Loranthus sp. are presented in Table 2.

Table 2. The antioxidant activity and strength of the mixed extract of Phyllanthus niruri, Euphorbia hirta, and Loranthus sp.

\begin{tabular}{|c|c|c|}
\hline $\begin{array}{l}\text { Plants } \\
\text { combination }\end{array}$ & $\begin{array}{c}\mathrm{IC}_{50} \text { value* } \\
(\mu \mathrm{g} / \mathrm{ml})\end{array}$ & $\begin{array}{c}\text { The antioxidant } \\
\text { power }\end{array}$ \\
\hline K-POO & $\begin{array}{c}508.5 \pm \\
16.9^{\mathrm{b}}\end{array}$ & Not active \\
\hline K-OEO & $\begin{array}{l}599.7 \pm \\
17.7^{\mathrm{a}}\end{array}$ & Not active \\
\hline K-OOL & $97.2 \pm 2.1^{\mathrm{d}}$ & Strong \\
\hline K-PEO & $\begin{array}{l}562.4 \pm \\
19.5^{\mathrm{ab}}\end{array}$ & Not active \\
\hline K-POL & $\begin{array}{l}272.1 \pm \\
32.4^{\mathrm{c}}\end{array}$ & Weak \\
\hline $\mathrm{K}-\mathrm{OEL}$ & $147.6 \pm 6.5^{\mathrm{d}}$ & Medium \\
\hline K-PEL & $\begin{array}{c}283.3^{ \pm} \\
81.1^{\mathrm{c}}\end{array}$ & Weak \\
\hline $\begin{array}{l}\text { Ascorbic } \\
\text { acid }\end{array}$ & $21.4 \pm 0.1^{\mathrm{e}}$ & Very strong \\
\hline \multicolumn{3}{|c|}{$\begin{array}{l}* \text { a-f letters indicate significant differences at } 5 \% \\
\text { significance level. The classification of antioxidant } \\
\text { power based on } \mathrm{IC}_{50} \text { value }(\mathrm{ppm}):<50 \text { : Very strong; } \\
50-100: \text { Strong; >100-250: Medium; >250-500: } \\
\text { Week; >500: Not active (Jun et al., 2003). The ratio } \\
\text { of } P \text {. niruri: E. hirta: Loranthus sp. in K-POO = } \\
\text { 1:0:0, K-OEO = 0:1:0, K-OOL= 0:0:1, K-PEO = }\end{array}$} \\
\hline
\end{tabular}

$0.5: 0.5: 0, \mathrm{~K}-\mathrm{POL}=0.5: 0: 0.5, \mathrm{~K}-\mathrm{OEL}=0: 0.5: 0.5$, and $\mathrm{K}-\mathrm{PEL}=0.33: 0.33: 0.33$.

In the condition of $P$. niruri and E. hirta as a single extract (K-POO and K-OEO respectively), the PRB activity of the extract was inactive (IC50 > 500 ppm), while the single extract of Loranthus sp. (KOOL) showed a strong antioxidant activity (IC50 < $100 \mathrm{ppm}$ ). Da'i et al. (2016) found that the ethanol extract of $P$. niruri from an Indian local market showed a potential of antioxidant activity, both in in vitro and in vivo model tests. In that study, the $\mathrm{IC}_{50}$ value in vitro test of the extract was $14.21 \pm 0.73$ $\mathrm{mg} / \mathrm{ml}$. In line with this result, the ethanol extract of $P$. niruri leaves grown in the Conservation and Cultivation Unit of the Bogor Indonesia Biopharmaceutical Research Center showed showed higher than water and methanol extracts, with the IC50 value of $14.5 \mathrm{~g} / \mathrm{ml}$ (Nurcholis et al., 2012). Research using aqueous extracts of $P$. niruri also showed that the ability was still low $\left(\mathrm{IC}_{50}\right.$ value 90.86 $\mathrm{g} / \mathrm{mL}$ ) compared to ascorbic acid ( $\mathrm{IC}_{50}$ value 25.31 $\mathrm{g} / \mathrm{mL}$ ) (Giribabu et al., 2014).

In all compositions, the FRS ability was still lower than that of ascorbic acid, which expressed a higher $\mathrm{IC}_{50}$ value of the mixture than ascorbic acid. The weak FRS ability of the mixed extracts compared to ascorbic acid was probably due to the extract being a crude extract produced by a maceration, while ascorbic acid was a pure compound. Further fractionation towards the extract may extract more antioxidant-specific compounds to increase its ability to scavenge free radicals. Abbasi et al. (2013) performed a stratified fractionation of a methanol extract of Euphorbia heterophylla, and it was found that the ethyl acetate fraction had a very strong antioxidant activity (the $\mathrm{IC}_{50}$ value using the DPPH method was $10.33 \mathrm{~g} / \mathrm{ml}$ ). The fractionation process can increase the antioxidant ability as seen in the comparison between the research results of Caroline et al. (2018) and Masruro and Tukiran (2017). The $\mathrm{IC}_{50}$ value of PRB with the DPPH method of E. hirta methanol extract was $72.20 \mathrm{~g} / \mathrm{ml}$ (Caroline et al. 2018), while the methanol fraction of graded maceration using n-hexane, chloroform, and methanol showed $30.02 \mathrm{~g} / \mathrm{ml}$ (Masruro \& Tukiran, 2017).

In the mixed composition, the presence of $P$. niruri and E. hirta that were K-PEO, K-POL, and KPEL (Figure 3A), K-PEO, K-OEL, and K-PEL (Figure 3B), and K-POL, K-OEL, and K-PEL (Figure 3C) significantly decreased the FRS ability of the mixture. The effect of $P$. niruri on the mixture containing Loranthus sp. decreased by $5-29 \%$, while the effect of E. hirta decreased by $8-23 \%$. On the other hand, the presence of Loranthus sp. in the mixture was able to increase the FRS activity of the 
mixture by $25-60 \%$. The composition of K-POL, KOEL, and K-PEL became more active in the presence of Loranthus sp. $\left(\mathrm{IC}_{50}\right.$ values are 272.1 ; 147.6; and $283.3 \mathrm{ppm}$, respectively). There might be compounds, both antioxidant and non-antioxidant, in $P$. niruri that were antagonistic to compounds in E. hirta and Loranthus sp., while the compounds between $E$. hirta and Loranthus sp. were synergistic and thus the PRB activity increased. Khanum et al. (2011) reported that there was a synergistic effect on the addition of Oreganum vulgare in increasing the PRB activity $( \pm 5 \%)$ of Trachyspermum ammi and Plectranthus amboinicus in all test concentrations, but they did not mention which compounds were synergistic. Some researchers have found that the combination of polyherbs that have antioxidant activity can be synergistic, additive, or antagonistic. The synergistic effect was seen in the combination of green tea with Phyllanthus emblica L., Punicagranatum, Cinnamomum cassia, Ginkgo biloba L., and Camellia sinesis Linn. (Jain et al., 2011), the combination of Pterospartum tridentatum and Cymbopogon citratus, and the combination of Gomphrena globosa and $C$. citratus (Bag \& Chattopadhyay, 2015).

A.
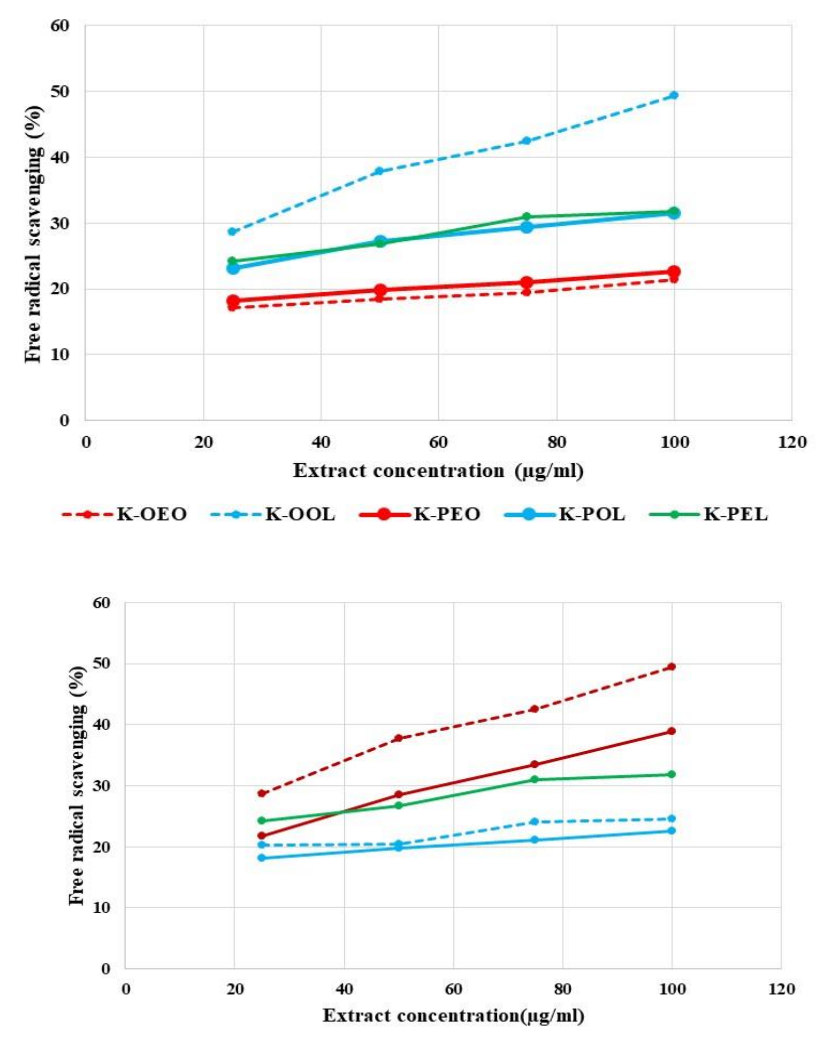

B.

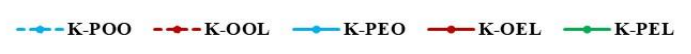

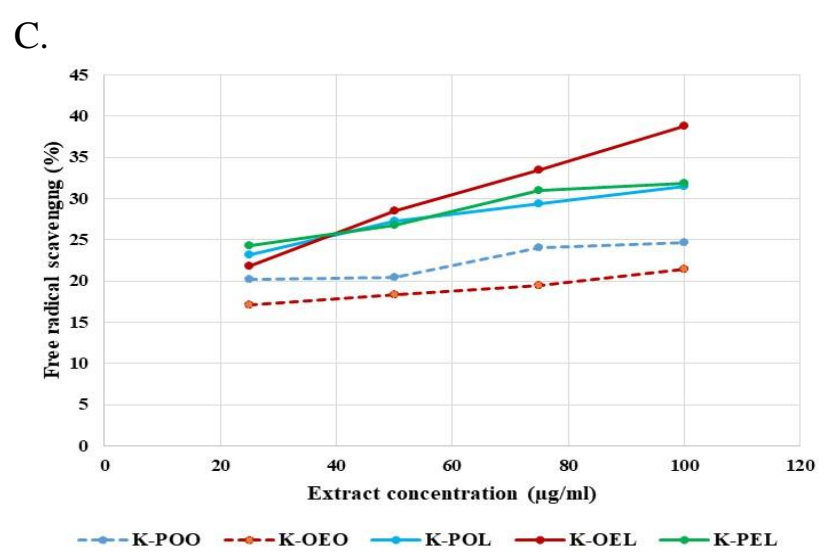

Figure 3. Patterns of the influence of one plant on another to the PRB activity in mixed extracts of $P$. niruri, E. hirta, and Loranthus sp. (A) The influence of the presence of $P$. niruri; (B) The influence of the presence of E. hirta. (C) The influence of the presence of Loranthus sp. The ratio of combination $P$. niruri: E. hirta: Loranthus sp. in K-POO = 1:0:0, K$\mathrm{OEO}=0: 1: 0, \mathrm{~K}-\mathrm{OOL}=0: 0: 1, \mathrm{~K}-\mathrm{PEO}=0.5: 0.5: 0, \mathrm{~K}-$ $\mathrm{POL}=0.5: 0: 0.5, \mathrm{~K}-\mathrm{OEL}=0: 0.5: 0.5$, and $\mathrm{K}-\mathrm{PEL}=$ 0.33:0.33:0.33.

Wang et al. (2015) conducted a study on essential oils from several herbs and spices including bay leaf, black pepper, coriander (seeds and leaves), cumin, garlic, ginger, mustard greens, shallots, and turmeric. The result showed that only the combination of coriander oil with cumin was synergistic, while the other combinations were additive to the antioxidant activity (Wang et al., 2015). The study towards the combination of Strobilanthes crispus, Phyllanthus niruri, Orthosiphon aristatus, and Stevia rebudiana (23.96:0.62:75.42:0) also showed the highest antioxidant activity (Rahim et al., 2018). The study of the combination between green tea with some abundant of phenolics and flavonoids herbs included Vitis vinifera, Phyllanthus emblica L., Punica granatum, Cinnamomum cassia, Ginkgo biloba L., and Camellia sinensis Linn. showed the syniergism relationship, that were the requirement of doses to scavenge the free radical compounds on the combination form lower than a single form (Jain et al., 2011).

\section{The content of flavonoid, phenolics, and ascorbic acid}

The pharmacological ability of herbal medicines is influenced by the presence of bio-active compounds, which usually are secondary metabolites (HaddadKashani et al., 2012; Prakash \& Gupta, 2013). The production of secondary metabolites in plants is determined by intrinsic factors in the form of the genes of the plant itself and extrinsic factors in the form of environmental conditions where they grow 
(climate and soil) (Figueirode et al., 2008). The quality, quantity, and biological activity of bio-active compounds in plants are related to the development stage of plants, plant organs, and the solvents used for extraction and isolation (Senguttuvan et al., 2014; Chekroun-Bechlaghem et al., 2019). The total of the secondary metabolite compounds and their antioxidant abilities are influenced by the solvent used, the extraction method used, and the plant part extracted (Rafińska et al., 2019). This research studied the antioxidant ability of three weeds that have been known to cure various diseases namely meniran ( $P$. niruri), patikan kebo (E. hirta), and benalu (Loranthus sp.).

Natural antioxidant compounds from plants are diverse, such as polyphenols (phenolic acids, flavonoids, anthocyanins, lignans and stilbenes), carotenoids (xanthophylls and carotenes), or vitamins (vitamins E and C) (Baiano \& Nobile, 2015; Manach et al. 2014). This study measured the content of flavonoids, phenolics, and vitamin $\mathrm{C}$ (ascorbic acid). In this study, the flavonoid levels were determined using quercetin as a standard compound. This compound is the most abundant polyphenol found in fruits and vegetables (Dabeek \& Marra, 2019). Quercetin is one of the flavonoid members that have the most efficient antioxidant ability. The structural nature of its strong antioxidant capacity is caused by several factors, including ortho-dihydroxy or catechol group in the B-ring, 2.3 double bonds, and hydroxyl substitution at position 3 and 5 (Ozgen et al., 2016). Flavonoids with $\mathrm{AlCl}_{3}$ forms a stable complex with C4 keto cluster and C3 or C5 hydroxyl cluster in flavones and flavonols (Petry et al., 2001). This complex gave a color that will be detected by a visible spectrophotometer. In the measurement of the total phenolic compounds, pure gallic acid was used as a standard to calculate the levels of phenolic compounds in the extract. Gallic acid has a hydroxy cluster and a conjugated double bond in the aromatic ring and can form a complex compound with the Folin-Ciocalteu reagent giving a deep blue color (Gulçin, 2012). Phenolic compounds can be released from the cell wall. Samples in the form of dry powder helped facilitate the release of a large number of bound phytochemical compounds into the medium during the extraction process, including phenolic compounds from the matrix (Ngamsuk et al., 2019).

This study used ethyl acetate as a solvent in the maceration process. Ethyl acetate is a solvent with a medium polarity $(0.228)$. This chemical nature allows the extraction process to attract various non-polar and polar compounds at a moderate level, making it possible to attract antioxidant parameter compounds such as flavonoids, phenolics, and vitamin C. Based on its structure, vitamin $\mathrm{C}$ has a carboxylate cluster is a polar compound, while for phenolic and flavonoids compounds which are the compound groups, some tend to be polar and some are non-polar, so they will be carried away during the extraction process. Phenolic compounds and flavonoids are secondary metabolites with various groups and are often found in vascular plants (Haminiuk et al., 2014). Therefore, flavonoid, phenolic, and ascorbic acid compounds will also be present in the three tested plants, and the test results are shown in Figure 3. Giribabu et al. (2014) conducted a phytochemical test on the aqueous extract of $P$. niruri dried leaves and it showed a positive presence of alkaloids, flavonoids, saponins, tannins, lignin, terpenoids, and curcumin.

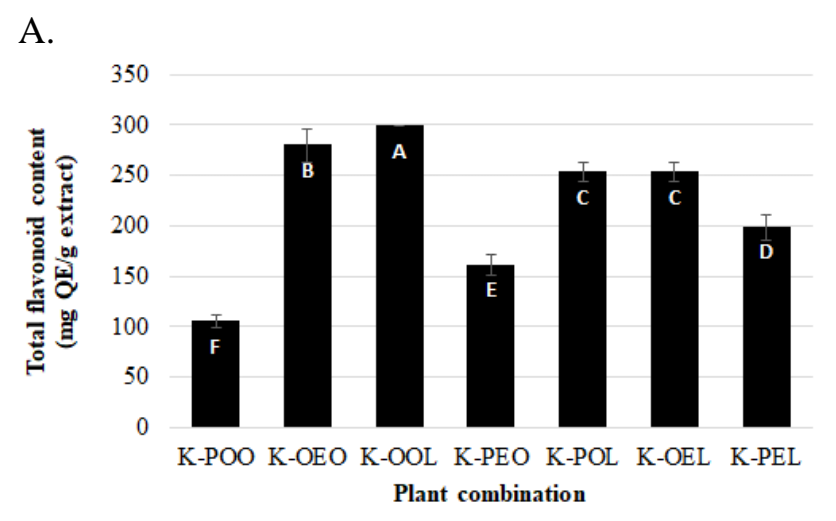

B.

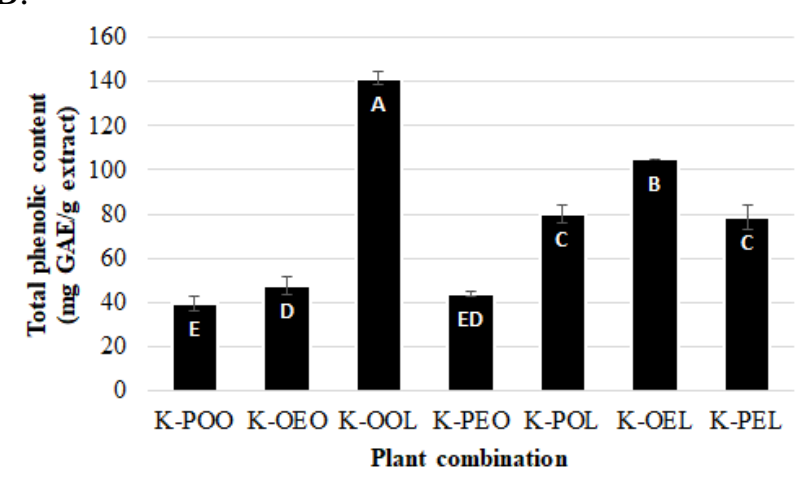

C.

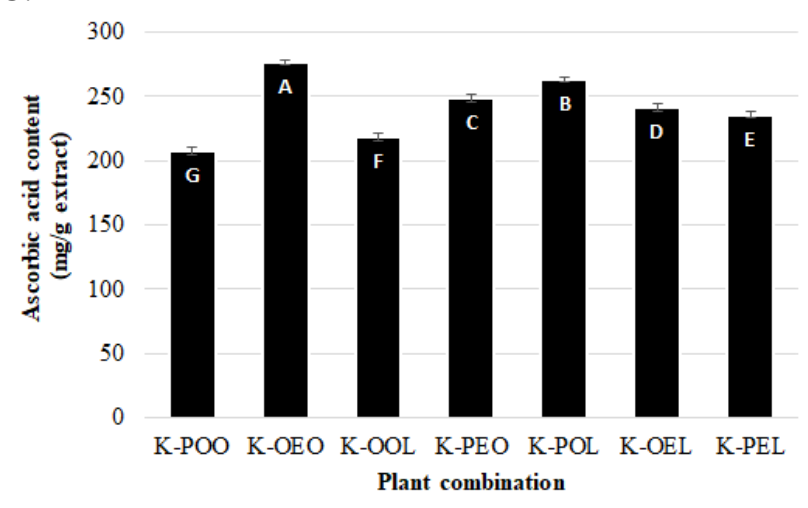

Figure 4. The level of total flavonoids (A) total phenolics; (B) and ascorbic acid; (C) contents in the extract of the P. niruri, E. hirta, dan Loranthus sp. combination. The ratio of combination $P$. niruri: $E$. 
hirta: Loranthus sp. in $\mathrm{K}-\mathrm{POO}=1: 0: 0, \mathrm{~K}-\mathrm{OEO}=$ $0: 1: 0, \mathrm{~K}-\mathrm{OOL}=0: 0: 1, \mathrm{~K}-\mathrm{PEO}=0.5: 0.5: 0, \mathrm{~K}-\mathrm{POL}=$ $0.5: 0: 0.5, \quad \mathrm{~K}-\mathrm{OEL}=0: 0.5: 0.5, \quad$ and $\mathrm{K}-\mathrm{PEL}=$ 0.33:0.33:0.33.

The synthesis and accumulation of nonenzymatic antioxidant compounds in plants might be caused by their natural tendency to respond to conditions of stress from their surroundings and/or their genetic structure that does exist to perform normal physiological functions to protect itself from microbial pathogens and animal herbivores (Kasote et al., 2015). Based on the environment where they grow, these three tested plants which are considered as weeds may produce antioxidant compounds for both of the reasons mentioned. In this research, the composition of K-POO, K-OEO, and K-OOL represented the single extract conditions of $P$. niruri, E. hirta, and Loranthus sp. In the single composition of $P$. niruri and E. hirta, the ascorbic acid level was the highest (207.4 \pm 2.89 and $276.1 \pm 1.67 \mathrm{mg} / \mathrm{g}$ extract), followed by flavonoid $(105.0 \pm 6.25$ and $280 \quad 0.0 \pm 16.54 \mathrm{mg}$ quercetin/g equivalent extract), and phenolic as the lowest content $(39.6 \pm 3.23$ and $47.6 \pm 3.88 \mathrm{mg}$ gallic $\mathrm{acid} / \mathrm{g}$ equivalent extract) with an inactive free radical scavenging activity $\left(\mathrm{IC}_{50}\right.$ value of $508.5 \pm$ $16.9 \mathrm{~B}$ and $599.7 \pm 17.7 \mathrm{~g} / \mathrm{ml})$. The single composition of Loranthus sp. had the highest flavonoid and phenolic content $(298.8 \pm 0.00 \mathrm{mg}$ quercetin/g equivalent extract and $141.5 \pm 2.85 \mathrm{mg}$ gallic acid/g equivalent extract) among all other compositions, but had the lowest ascorbic acid content $(218.7 \pm 3.01 \mathrm{mg} / \mathrm{g}$ extract $)$, while the PRB activity was strong ( IC $_{50}$ value of $97.2 \pm 2.1 \mathrm{~g} / \mathrm{ml}$ ). When it is associated with the ability of antioxidants, it can be seen that the presence of phenolics has most prominent positive correlation with it. The higher the level of phenolic compounds, the stronger the antioxidant ability. The Loranthus sp. extract. (KOOL) with the highest phenolic acid showed the highest antioxidant activity.

In the single extract of $P$. niruri and E. hirta (K$\mathrm{POO}$ and K-OEO) with low phenolic content, the antioxidant activity was also low. In the combination of $P$. niruri and $E$. hirta (K-PEO), the activity remained low. The antioxidant activity turned higher when Loranthus sp. was put into the mixture. Phenolic compounds generally have one or more aromatic rings with one or more hydroxyl clusters. The ability of phenolic compounds to act as antioxidants depends on the redox characteristics of the phenolic hydroxyl clusters and the potential of electron delocalization in their chemical structure (Gulçin, 2012). Loranthus sp. might be synthesizing large amounts of phenolic compounds which contain many hydroxyl clusters because it is generally assumed that the antioxidant capacity of phenolics will increase with the amount of free hydroxyl and side-chain conjugation to an aromatic ring. Some researchers stated that phenolic compounds, which consist of phenolic acids, flavonoids, lignans, stilbenes, and tannins are the most important because in both in vitro and in vivo test results, this type of compound shows a strong antioxidant activity (Myburgh, 2014; Blokhina et al., 2003; Duthi et al., 2000).

The phenolic content in the ethyl acetate extract of stem bark of Loranthus pulverulentus, which partitioned from methanol : water extract $(90: 10)$ extract was $151 \pm 2.1$ to $396 \pm 1.6 \mathrm{GAE} / \mathrm{g}$ extract while the leaf was $137 \pm 0.9$ to $430 \pm 2.2 \mathrm{mg}$ GAE/g extract (Raza et al., 2013). The difference of results within this study may be influenced by the extraction method and the Loranthus sp. species. The ethanolic extract of $P$. niruri contained a total of $81.59 \pm 2.85 \mathrm{mg}$ phenolic equivalent to gallic acid/g extract (Da'i et al., 2016). The study of $E$. hirta leaf extract showed that the ethanolic extract contained a higher level of phenolic compounds $(291.74 \pm 2.46 \mathrm{mg}$ gallic acid equivalent/g extract) and flavonoids $(40.32 \pm 1.67 \mathrm{mg}$ quercetin equivalent/g extract) compared to methanol and water extracts (Asha et al., 2016).

The same thing was found in the antioxidant activity as the results of the DPPH test, the hydroxyl radical scavenging test, and the superoxide radical scavenging test showed that the antioxidant activity of ethanol extract was stronger than the other two extracts, namely methanol dan aqueous extract (Asha et al., 2016). This phenomenon that antioxidant activity of ethanol extract stronger than aqueous extract was also seen in a study by Venkatachalam et al. (2018). This indicated that a higher content of bioactive compounds will result in a higher antioxidant activity as well. Ethanol extract, which had a higher flavonoid content than an aqueous extract, also exhibited stronger antioxidant abilities based on the DPPH free radical scavenging test, ferric reducing power (FRAP) determination, and Lipid peroxidation inhibition (Maya et al. 2018). The phytochemical test of ethanol and aqueous extract of E. hirta resulted in positive for tannins, flavonoids, coumarins, reducing sugars, steroids, and triterpenoids. The FRS activity using the DPPH test for the ethanol extract was stronger $\left(\mathrm{IC}_{50}\right.$ value of $4.93 \pm 0.40 \mathrm{~g} / \mathrm{mL})$ than aqueous extract $\left(\mathrm{IC}_{50}\right.$ value of $46.33 \pm 3.21 \mathrm{~g} / \mathrm{mL}$ (Maya et al., 2018). The level of phenolic compounds in the aqueous extract of E. hirta was $52.92 \pm 5.62 \mathrm{mg}$ equivalent to gallic 
acid/g extract with an FRS activity $\mathrm{IC}_{50}$ value of $175 \pm .098 \mathrm{mg} / \mathrm{ml}$ (Sharma et al., 2007). Do provide more sentences regarding the role of solvent used in extraction related to this study to summerize the information mentioned above to provide a clear and good paragraph. Haddad-Kashani et al., 2012 stated that the pharmacological properties of natural product depend on the content of secondary metabolites. Generally, the polarity of secondary metabolite compounds is different so that the use of solvent for extraction affected the type of compound to be extracted (Visht \& Chaturvedi, 2012). Extraction using short-chain alcohol as solvents could extract compounds such as terpenoid, saponin, phenolic compounds, and/or flavonoids (Wu et al., 2011; Lalee et al., 2012). In this research, all of the extract contained both flavonoid and phenolic acid, although we used ethyl acetate as solvent extraction. This is may be cause of ethyl acetate is a semipolar solvent. Ethyl acetate is could attract both of lipophilic and hydrophilic compounds (Hardiana et al., 2012). Flavonoid are an intermediates compound which could act as lipophilic and hydrophilic (Middleton et al., 2000). The results of research by Sulmartiwi et al. (2018) showed that phenolic compounds can be dissolved using non-polar, semi-polar, and polar solvents.

The research on the antioxidant activity of benalu (Loranthus sp), meniran ( $P$. niruri) and patikan kebo (E. hirta) has been carried out and reported by many researchers, but research is still limited to testing the antioxidant activity of each plant, and no studies have reported the antioxidant activity of the combination of the three plants. Based on the results of this study, it was found that the combination of the three herbal plants (Loranthus sp, P. niruri and E. hirta) had higher antioxidant activity than single plants. The presence of Loranthus sp in each plant mixture composition tested significantly increased antioxidant activity. The results of this study are expected to provide new information that can be used in the development of herbal medicines to increase endurance and traditional medicine. Generally, in traditional medicine using herbal medicine, the ingredients used are a mixture of various species of medicinal plants, therefore the information obtained from this study is expected to be additional useful information for the development of herbal medicine.

\section{CONCLUSION}

Free radical scavenging activity (FRS) in mixed extracts of Phyllanthus niruri, Euphorbia hirta, and Loranthus sp. is dose dependent. The higher doses of the extract, the higher ability of Free Radical Scavenging. The strongest of FRS ability was KOOL composition (ratio of combination $P$. niruri: $E$. hirta: Loranthus sp. $=0: 0: 1)$ with $\mathrm{IC}_{50}$ value of $97.2 \pm 2.1 \mathrm{ppm}$. In the composition of the mixture tested, the presence of Loranthus sp. significantly increased antioxidant ability whereas $P$. niruri attenuated. Phenolic compounds were more correlated with the ability of antioxidants than flavonoid or ascorbic acid. The ratio of combination P. niruri: E. hirta: Loranthus sp.=0:0:1 (K-OOL) had the highest of flavonoids and phenolics content, which were $298.8 \pm 0.00 \mathrm{mg}$ quercetin equivalent/g extract and $141.5 \pm 2.85 \mathrm{mg}$ gallic acid equivalent/g extract, respectively. The highest of ascorbic acid content showed by K-OEO composition (ratio of $P$. niruri: E. hirta: Loranthus sp. $=0: 1: 0)$, which was $276.1 \pm 1.67 \mathrm{mg} / \mathrm{g}$ extract.

\section{ACKNOWLEDGEMENT}

The author would like to thank Satya Wacana Christian University for funding this research and publication through the 2020 Fundamental Research Program.

\section{REFERENCES}

Abbasi, M. A., Saleem, H., Aziz-ur-Rehman, \& Riaz, T., (2013). Determination of antioxidant activity and phytoconstituent screening of Euphorbia heterophylla Linn., Br. J. Pharm. Res, 3(2), 202216.

Aminudin, Andarwulan, N., Palupi, N. S., \& Arifiantini, I. (2020). Characteristics and antioxidant activity of kebar grass (Biophytum petersianum) extract. Biosaintifika, 12(2), 178185.

Asha, S., Thirunavukkarasu, P., Mani, M., \& Sadiq, A. M. (2016). Antioxidant activity of Euphorbia hirta Linn leaves extracts. European $J$ Med Plants, 14(1), 1-14.

Bag, A., \& Chattopadhyay, R. R. (2015). Evaluation of synergistic antibacterial and antioxidant efficacy of essential oils of spices and herbs in combination. PLoS One, 10(7), e0131321-37.

Bahmani, F., Kazemeini H., HoseinzadehChahkandak, F., Farkhondeh, T., \& Sedaghat, M. (2019). Sedation with medicinal plants: A review of medicinal plants with sedative properties in Iranian ethnoblotanical documents. Plant Biotechnology Persa, 1(1), 13-24.

Balogh, T., \& Szarka, A. (2016). A comparative study: methods for the determination of ascorbic acid in small and middle sized food analytic laboratories. Acta Aliment, 45(3), 354-362. 
Bandoniene, D. \& Murkovic, M. (2002). The detection of radical scavenging compounds in crude extract of borage (Borago officinalis L.) by using an on-line HPLC-DPPH method. $J$ Biochem Biophys Methods, 53(1-3), 45-49.

Blokhina, O., Virolainen, E., \& Fagerstedt, K. V. (2003). Antioxidants, oxidative damage and oxygen deprivation stress: a review. Ann Bot, 91(2), 179-94.

Baiano, A., \& Nobile M. A. D. (2015). Antioxidant compounds from vegetable matrices: Biosynthesis, occurrence, and extraction systems. Crit. Rev. Food Sci. Nutr, 56(12), 2053-2068.

Burda, S. \& Oleszek, W. (2001). Antioxidant and antiradical activities of flavonoids. J Agric Food Chem, 49(6), 2274-2279.

Caroline, J. R., Ilakiya, A., Deepika, R., Sujatha, M., \& Sivaraji, C. (2018). Antipsoriasis, antioxidant, and antimicrobial activities of aerial parts of Euphorbia hirta. Asian J Pharm Clin Res, 11 (9), 513-517.

Chekroun-Bechlaghem, N., Belyagoubi-Benhammou N., Belyagoubi, L., Gismondi, A., Nanni, V., Di Marco, G., Canuti, L., Canini, A., El Haci, I., \& Atik, B. F. (2019). Phytochemical analysis and antioxidant activity of Tamarix africana, Arthrocnemum macrostachyum and Suaeda fruticosa, three halophyte species from Algeria. Plant Biosyst, 153(6), 843-852.

Dabeek, W. M. \& Marra, M.V. (2019). Dietary quercetin and kaempferol: bioavailability and potential cardiovascular-related bioactivity in humans. Nutrients, 11, 2288-2306.

Da'i, M., Wahyuni, A. S., Ika T. D. K., Azizah, T., Suhendi, A., \& Saifudin, A. (2016). Antioxidant activity of Phyllanthus niruri L. herbs: in vitro and in vivo models and isolation of active compound. Natl J Physiol Pharm Pharmacol, 6(1), 32-37.

Deng, G. F., Shen, C., Xu, X. R., Kuang, R. D., Guo, Y. J., Zeng, L. S., Gao, L. L., Lin, X., Xie, J. F., \& Xia, E. Q. (2012). Potential of fruit wastes as natural resources of bioactive compounds. Int. J. Mol. Sci, 13(7), 8308-8323.

Dontha, S. (2016). A review on antioxidant methods. Asian J Pharm Clin Res, 9(2), 14-32.

Duthie, G. G., Duthie, S. J., \& Kyle, J. A. (2000). Plant polyphenols in cancer 54. and heart disease: implications as nutritional antioxidants. Nutr. Res. Rev, 13(1), 79-106.

Eloziia, N., Kumar, N., Kothiyal, P., Deka, P., \& Nayak, B. K. (2017). A review on antidepressant plants. Journal of Pharmacy Research, 11(5), 382396.

Figueirode, A. C., Barroso, J. G., Pedro, L. G., \& Scheffer, J. J., (2008). Factors affecting secondary metabolite production in plants: volatile components and essential oils. Flavour Fragr. J, 23(4), 213-226.

Giribabu, N., Rao, P. V., Kumar, K. P., Muniandy, S., Rekha, S. S., \& Salleh, N. (2014). Aqueous extract of Phyllanthus niruri leaves displays in vitro antioxidant activity and prevents the elevation of oxidative stress in the kidney of streptozotocininduced diabetic male rats. Evid. Based Complementary Altern. Med, 2014, 1-10.

Gulçin, I. (2012). Antioxidant activity of food constituents: an overview. Arch. Toxicol, 86, 345391.

Haddad-Kashani, H., Seyed-Hosseini, E., Nikzad, H., \& Aarabi, M.H. (2012). Pharmacological properties of medicinal herbs by focus on secondary metabolites. Life Science Journal, 9(1), 509-520.

Haidara, M., Dénou, A., Haddad, M., Camara, A., Traoré, K., Aubouy, A., Bourdy, G., \& Sanogo, R. (2020). Evaluation of anti-inflammatory, antipyretic, analgesic, and hepatoprotective properties of Terminalia macroptera. Planta Med. Int. Open, 7, e58-e67.

Haminiuk, C. W. I., Plata-Oviedo, M. S. V., de Mattos, G., Carpes, S. T., \& Branco, I. G. (2014). Extraction and quantification of phenolic acids and flavonols from Eugenia pyriformis using different solvents. J. Food Sci. Technol, 51(10), 2862-2866.

Hardiana, R., Rudiyansyah, \& Zaharah, T. A. (2012). Aktivitas antioksidan senyawa golongan fenol dari beberapa jenis tumbuhan famili Malvaceae. $J K K$, 1(1), 8-13.

Ibrahim, D., Hong, L. S., \& Kuppan, N. (2013). Antimicrobial activity of crude methanolic extract from Phyllanthus niruri. Nat. Prod. Commun, 8(4), 493-496.

Iswari, R. S. \& Susanti, R. (2016). Antioxidant activity from various tomato processing. Biosaintifika, 8(1), 129-134.

Jain, D. P., Pancholi, S. S., \& Patel, R. (2011). Synergistic antioxidant activity of green tea with some herbs. J Adv Pharm Technol Res., 2(3), 17783.

Jun, M., Fu, H.-Y., Hong, J., Wan, X., Yang, C. S., \& Ho, C.-T. (2003). Comparison of antioxidant activities of isoflavones from kudzu root (Pueraria lobata Ohwi). J. Food Sci, 69, 21122127.

John, B., Sulaiman, C. T., George, S., \& Reddy, V. R. K. (2014). Total phenolics and flavonoids in selected medicinal plants from Kerala. Int. J. Pharm. Pharm. Sci, 6(1), 406-408.

Karakaya, S., Koca, M., Sytar, O., \& Duman, H. (2019). The natural phenolic compounds and their antioxidant and anticholinesterase potential of 
herb Leiotulus dasyanthus (K. Koch) Pimenov \& Ostr. Nat. Prod. Res, 18, 1-3.

Kasmiyati, S., Kristiani, E. B. E., Herawati, M. M. \& Sukmana, A. B. A. (2021). Antibacterial activity and flavonoids content of Artemisia cina Berg. ex Poljakov ethyl acetate extracts. Biosaintifika, 13(1), 106-112.

Kasote, D. M., Katyare, S. S., Hegde M. V., \& Bae, H. (2015). Significance of antioxidant potential of plants and its relevance to therapeutic applications. Int. J. Biol. Sci., 11(8), 982-991.

Khanum, H., Ramalakshmi, K., Srinivas, P., \& Borse, B. B., (2011). Synergistic antioxidant action of oregano, ajowan and borage extracts. Food Nutr. Sci., 2, 387-392.

Krishnaiah, D., Sarbatly, R., \& Nithyanandam, R. (2011). A review of the antioxidant potential of medicinal plant species. Food Bioprod Process, 89, 217-33.

Kristiani, E. B. E., Nugroho, L. H., Moeljopawiro, S. \& Widyarini, S. (2016). Characterization of volatile compounds of Albertisia papuana Becc root extracts and cytotoxic activity in breast cancer cell line T47D. TJPR, 15(5), 959-964

Kristiani, E. B. E., Kasmiyati, S., \& Herawati, M. M. (2021). The cytotoxic and apoptotic effects of wild and polyploidy genotype of Artemisia cina extracts on the WiDr colon and HTB-183 lung cancer cell lines. Biodiversitas, 22(7), 2844-2852.

Kumar, S. \& Pandey, A. K. (2015) Free Radicals: health implications and their mitigation by herbals. BJMMR, 7(6), 438-457.

Lalee, A., Pal, P., Bhattacharaya, B., \& Samanta, A. (2012). Evaluation of anticancer activity of Aevera sanguinolenta (L.) (Amaranthaceae) on ehrlich cell induced Swiss Mice. Int. J. Drug Dev. Res, 4(1), 203-209.

Mahmood A., Mahmood A., \& Tabassum A. (2011). Ethnomedicinal survey of plants from District Sialkot, Pakistan. J App Pharm, 02(03), 212-220.

Manach, C., Scalbert, A., Morand, C., Remesy, C., \& Jimenez, (2004). Polyphenols: food sources and bioavailability. Am. J. Clin. Nutr, 79(5), 727-747.

Maity, S., Chatterjee, S., Variyar, P. S., Sharma, A., Adhikari, S., \& Mazumder, S. (2013). Evaluation of antioxidant activity and characterization of phenolic constituents of Phyllanthus amarus root. J. Agric. Food Chem, 61(14), 3443-3450.

Majid, M., Khan, M. R., Shah, N. A., Ul Haq, I., Farooq, M. A., Ullah, S., Sharif, A., Zahra, Z. Younis, T., \& Sajid, M. (2015). Studies on phytochemical, antioxidant, anti-inflammatory and analgesic activities of Euphorbia dracunculoides. BMC Complement Altern Med, 15, 349-363.

Masruro, E. \& Tukiran. (2017). Aktivitas antioksidan dan identifikasi senyawa hasil isolasi dari ekstrak methanol tanaman Euphorbia hirta. UNESA Journal of Chemistry, 6(1), 1-5.

Maya, D., Balé, B., Samson, G., Basile, T., \& Raymond, B. (2018). Phytochemical composition, toxicity, antioxidant and lactogenic activities of euphorbia hirta (L.). Int. J. Adv. Res, 6(8), 322335.

Middleton E. Jr., Kandaswami, C., Theoharides, T. C. 2000. The effects of plant flavonoids on mammalian cells: implications for inflammation, heart disease, and cancer. Pharmacol Rev, 52(4), 673-751.

Myburgh KH. (2014). Polyphenol supplementation: benefits for exercise performance or oxidative stress? Sports Med, 44(Supll 1), S57-S70.

Ngamsuk, S., Huang, T-C., \& Hsu, J-L. (2019). Determination of phenolic compounds, procyanidins, and antioxidant activity in processed Coffea arabica L. leaves. Foods, 8, 389-401.

Nurcholis, W., Priosoeryanto, B. P., Purwakusumah, E. D. Katayama, T., \& Suzuki, T. (2012). Antioxidant, cytotoxic activities and total phenolic content of four Indonesian medicinal plants. Valensi, 2(4), 501-510.

Ozgen, S., Kilinc, O. K., \& Selamoglu, Z. (2016). Antioxidant activity of quercetin: a mechanistic review. Turkish. J. Agric. Sci. Technol, 4(12), 1134-1138.

Petrovska B. B. (2012). Historical review of medicinal plants' usage. Pharmacogn Rev, 6(11), $1-5$.

Petry, R. D., Ortega, R. D., \& Silva, W. B. (2001). Flavonoid content assay: influence of the reagent concentration and reaction time on the spectrophotometric behavior of the aluminium chloride - flavonoid complex. Pharmazie, 56(6), 465-70.

Prakash, E \& Gupta D. K. (2013). In vitro study of extracts of Ricinus communis Linn on human cancer cell lines. Journal of Medical Sciences and Public Health, 2 (1), 15-20.

Rafińska, K., Pomastowski, P., Rudnicka, J., Krakowska, A., Maruśka, A., Narkute, M., \& Buszewski, B. (2019). Effect of solvent and extraction technique on composition and biological activity of Lepidium sativum extracts. Food Chem, 289, 16-25.

Rahim, N. F. A., Muhammad, N., Abdullah, N., Talip, B. H. A., \& Dusuki, N. J. S. (2018) Polyherbal formulations with optimum antioxidant properties. AIP Conference Proceedings 2016, 020007.

Rahman, Md. R., Ali, M., Sharif, M., \& Tajmim, A. (2017). A review study on the traditional plants has potential antidepressant property. MOJ Cell Sci Rep, 4(5), 138-145. 
Raza, M. A., Kausar, R., Rana, F. A., Danish, M., Shahwar, D., \& Anwar, F. (2013). Loranthus pulverulentus: a potent source of natural antioxidants and alternative medicine. J. Chem., 2013(5), 1-7.

Safriani, N., Rungkat, F. Z., Yuliana, N. D., \& Prangdimurti, E. (2021). Immunomodulatory and antioxidant activities of select Indonesian vegetables, herbs, and spices on human lymphocytes. Int. J. Food Sci, 2021, 1-12.

Senguttuvan, J., Paulsamy, S., \& Karthika, K. (2014). Phytochemical analysis and evaluation of leaf and root parts of the medicinal herb, Hypochaeris radicata $\mathrm{L}$. for in vitro antioxidant activities. Asian Pac. J. Trop. Biomed, 4(1), S359-67.

Sharma, N. K., Dey, S., \& Prasad, R. (2007). In vitro antioxidant potential evaluation of Euphorbia hirta L. Pharmacologyonline, 1, 91-98.

Sofowora, A., Ogunbodede, E., \& Onayade, A. (2013). The role and place of medicinal plants in the strategies for disease prevention. Afr. J. Tradit. Complement. Altern. Med, 10(5), 210-229.

Sulmartiwi, L., Pujiastuti, D. Y., Tjahjaningsih W., Jariyah. (2018). Potential of mangrove Avicennia rumphiana extract as an antioxidant agent using multilevel extraction. In: IOP Conf. Series: Earth and Environmental Science, 137, 012075.

Xu, D-P., Li Y., Meng X., Zhou T., Zhou Y., Zheng J., Zhang J-J., \& Li H-B. (2017). Natural antioxidants in foods and medicinal plants: extraction, assessment and resources. Int. J. Mol. Sci, 18(1), 96-127.
Venkatachalam, D., Samuel, S.T., Muddukrishniah, K., \& Vijayan, S. (2018). Screening of Euphorbia hirta extracts for antioxidant activity. Indian. $J$. Med. Res. Pharm. Sci, 5(6), 1-15.

Visht, S. \& Chaturvedi, S. (2012). Isolation of natural products. Current Pharma Research, 2(3), 584599.

Wafaa, N., Sofiane, G., \& Mouhamed, K. (2016). The antioxidant and antimicrobial activities of flavonoids and tannins extracted from Phlomis bovei De Noé. Eur. J. Exp. Biol, 6(3), 55-61.

Wang, S., Wang, D., \& Liu, Z. (2015). Synergistic, additive and antagonistic effects of Potentilla fruticosa combined with EGb761 on antioxidant capacities and the possible mechanism. Ind. Crop Pro, 67, 227-238.

Wu, Q., Wang, Y., Guo, M. (2011). Triterpenoid saponin from the seeds of Celosia Argentea and antitumor activity. Chem. Pharm. Bull, 59(5), 666671.

Yusufoglu, H. S. (2014). Analgesic, antipyretic, antiinflammatory, hepatoprotective and nephritic effects of the aerial parts of Pulicaria arabica (Family: Compositae) on rats. Asian Pac. J. Trop. Med, 7(Suppl 1), S583-S590.

Zainol, M. K., Abd-Hamid, A., Yusof, S., \& Muse, R. (2003). Antioxidative activity and total phenolic compounds of leaf, root and petiole of four accessions of Centella asiatica (L.) Urban. Food Chem, 81(44), 575-581. 